\title{
Al-Madãris
}

VOL. 1, NO. 12020

E-ISSN: 2745-9950

https://journal.staijamitar.ac.id/index.php/almadaris

\section{PENERAPAN MODEL PEMBELAJARAN JIGSAW UNTUK MENINGKATKAN HASIL BELAJAR SISWA PEMBELAJARAN BAHASA INDONESIA MATERI TEKS EKSEMPLUM KELAS II SEMESTER I MTSN 1 ACEH UTARA TAHUN PELAJARAN 2017/2018}

\author{
Mutia Zakiyanti \\ MTsN 1 Aceh Utara \\ mutizaky@gmail.com
}

\begin{abstract}
This study aims to find out how the application of the Jigsaw Learning Model for the Exemplum Text material, as well as the improvement of student learning outcomes of Indonesian language learning material for the Exemplum Text for Students in Class IX / 2 Semester 1 MTsN 1 of North Aceh in the 2017/2018 academic year. This research is a research with a qualitative approach. The sample of this study amounted to 38 students. Data collection was carried out by means of Classroom Action Research stages. Based on the results of research data analysis, it is concluded that the application of the Jigsaw Learning Model to the Exemplum Text Material in Class IX / 2 MTsN 1 of North Aceh can actually improve student learning outcomes. The acquisition of student learning outcomes can be seen in the average class which shows an increase from cycle I to cycle II, the final result is above the minimum standard (76\%), namely $90.5 \%$. The improvement of student learning outcomes in the Exemplum Text material can also be seen from the results of teacher observations which show that with the implementation of the action in this study almost all students can master the Exemplum Text material properly. Before implementing the Jigsaw learning model as an effort to improve student learning outcomes. Where at the end of the cycle the results obtained in addition to this action can improve student learning outcomes of the exemplum text material, all students can also increase their interest and motivation in learning the exemplum text material.
\end{abstract}

Keywords: Jigsaw learning model, Learning Outcomes and Exemplum Text Materials

Al-Madãris, Volume 1 (1), 2020 


\section{A. Pendahuluan}

Tercapainya tujuan pembelajaran dapat dibuktikan salah satunya dengan hasil belajar siswa, seperti yang dikatakan Sardiman (2011) bahwa tujuan pengajaran inilah yang merupakan hasil belajar bagi siswa setelah melakukan proses belajar dibawah bimbingan guru dalam kondisi yang kondusif. Proses pembelajaran akan lebih hidup dan menjalin kerjasama diantara peserta didik, maka proses pembelajaran dengan paradigma lama harus diubah dengan paradigma baru yang dapat meningkatkan kreativitas peserta didik dalam berpikir, arah pembelajaran yang lebih kompleks tidak hanya satu arah sehingga proses belajar mengajar akan dapat meningkatkan kerjasama diantara peserta didik dengan guru dan peserta didik dengan peserta didik, maka dengan demikian peserta didik yang kurang akan dibantu oleh peserta didik yang lebih pintar sehingga proses pembelajaran lebih hidup dan hasilnya lebih baik.

Pembelajaran Bahasa Indonesia membutuhkan proses pembelajaran yang mengarah pada proses aktif pada diri peserta didik. Pembelajaran yang aktif ini belum dilakukan di kelas 2. Kenyataan selama ini berdasarkan pengalaman peneliti di MTsN 1 Aceh Utara. Proses pembelajaran Bahasa Indonesia yang dilakukan masih menggunakan metode konvensional yaitu ceramah dan tanya jawab, sehingga siswa pasif yang hanya duduk, diam, dengar, catat dan hafal tanpa menggunakan alat peraga dan media pembelajaran. Sehingga siswa terkesan pasif dalam belajar, hanya menerima apa yang disampaikan oleh guru. Kegiatan ini mengakibatkan siswa kurang ikut berpartisipasi dalam kegiatan pembelajaran yang cenderung menjadikan mereka cepat bosan dan malas belajar. Dilihat dari nilai ketuntasan pada semester ganjil tahun ajaran 2016/2017 siswa yang tuntas dengan KKM 65 pada pembelajaran Bahasa Indonesia hanya 40\% dari jumlah seluruh siswa rata-rata siswa kurang memahami materi Teks Eksemplum.

Melihat kondisi tersebut di atas, maka dirasa perlu adanya suatu perubahan baru dalam pelaksanaan pembelajaran Bahasa Indonesia di MTsN 1 Aceh Utara agar siswa lebih aktif dan kreatif sehingga bisa berkembang sesuai dengan tingkat kemampuan masing-masing. Dalam usaha untuk meningkatkan keaktifan dan kekreatifan siswa dalam proses pembelajaran bisa dengan menggunakan salah satu model dari pembelajaran kerjasama atau gotong royong yang sering disebut cooperative learning. Model pembelajaran yang diterapkan salah satunya adalah model pembelajaran Jigsaw untuk memperbaiki proses pembelajaran mata pelajaran Bahasa Indonesia. Dalam Jigsaw siswa diharapkan dapat lebih mudah memahami materi Teks Eksemplum.

\section{B. Review Literatur}

Model pembelajaran tipe Jigsaw merupakan salah satu bentuk pembelajaran kooperatif. Pembelajaraan kooperatif atau cooperative laerning adalah rangkaian kegiatan belajar yang dilakukan oleh siswa dalam kelompok-kelompok tertentu untuk mencapai tujuan pembelajaran yang telah di rumuskan (Sanjaya, 2006:241). Dibandingkan dengan pembelajaran lainnya pembelajaran kooperatif memiliki ciri-ciri sebagai berikut (1) Siswa bekerja dalam kelompok secara koopatif untuk menuntaskan materi belajar (2) Kelompok di bentuk dari siswa

Al-Madãris, Volume 1 (1), 2020 
yang mempunyai kemampuan tinggi, sedang, dan rendah. (3) Bila memungkinkan anggota kelompok berasal dari ras, budaya, suku jenis kelamin beragam (4) Penghargaan lebih berorientasi kepada kelompok dari pada individu (Trianto, 2011:47).

Dalam (Trianto, 2011: 56) pembelajaran kooperati tipe Jigsaw dibagi menjadi 6 enam langkah yaitu:

1) Siswa dibagi atas beberapa kelompok (tiap kelompok anggotanya 5-6 orang);

2) Materi pelajaran di berikan pada siswa dalam bentuk teks yang telah dibagi-bagi menjadi beberapa sub bab;

3) Setiap anggota kelompok membaca sub bab yang di tugaskan dan bertangung jawab untuk mempelajarinya;

4) Anggota dari kelompok lain yang telah mempelajari sub bab yang sama bertemu dalam kelompok-kelompok ahli untuk mendiskusikanya;

5) Setiap anggota kelompok ahli setelah kembali ke kelompoknya bertugas mengajar teman-temannya;

6) Pada pertemuan dan diskusi kelompok asal, siswa di kenai tagihan berupa kuis individu.

Hasil belajar pada hakekatnya adalah perubahan tingkah laku yang diperoleh seseorang setelah mengalami aktivitas belajar. Adapun perubahan tingkah laku sebagai hasil belajar pengertiannya luas mencakup bidang kognitif, afektif dan psikomotorik. Hasil belajar juga merupakan realisasi atau pemekaran dari kecakapan-percakapan potensial atau kapasitas yang dimiliki seseorang. Berikut ini berapa definisi tentang hasil belajar atau prestasi belajar antara lain:

1. Menurut Winkel: "Hasil belajar adalah perubahan yang mengakibatkan manusia yang berubah dalam sikap dan tingkah lakunya" (Purwanto, 2009: 45).

2. Hasil belajar menurut Gagne antara lain:

a) Informasi Verbal yaitu kualitas mengungkapkan pengetahuannya dalam bentuk bahasa, baik lisan maupun tulisan.

b) Ketrampilan intelektual yaitu kemampuan mempresentasikan konsep dan lambang.

c) Strategi kognitif yaitu keaktifan menyalurkan aktifitas kognitifnya sendiri.

d) Ketrampilan motorik yaitu kemampuan melakukan serangkaian gerakan dalam urusan dan koordinasi.

e) Sikap adalah kemampuan untuk menerima atau menolak objek berdasarkan penilaian terhadap objek (Agus Suprijono, 2010:5-6).

Hasil belajar yang dicapai merupakan hasil interaksi berbagai faktor yang mempengaruhinya baik faktor dalam diri atau dari luar diri individu. (Abu Ahmadi, 2004:138). Berkaitan dengan hasil belajar, dapat peneliti bedakan menjadi tiga aspek yaitu kognitif, afektif dan psikomotor. Ranah kognitif (berkaitan dengan daya pikir, pengetahuan, dan penalaran) berorientasi pada kemampuan siswa dalam berfikir dan bernalar yang mencakup kemampuan siswa dalam mengingat sampai memecahkan masalah, yang menuntut siswa untuk 
menggabungkan konsep-konsep yang telah dipelajari sebelumnya. Ranah kognitif ini berkenaan dengan prestasi belajar dan dibedakan dalam enam tahapan, yaitu pengetahuan, pemahaman, penerapan, analsisi, sintesis, dan eveluasi.

Ranah afektif (berkaitan dengan perasaan atau kesadaran, seperti perasaan senang atau tidak senang yang memotivasi seseorang untuk memilih apa yang disenangi) berorientasi pada kemampuan siswa dalam belajar menghayati nilai objek-objek yang dihadapi melalui perasaan, baik objek itu berupa orang, benda maupun peristiwa. Ciri lain terletak dalam belajar mengungkapkan perasaan dalam bentuk ekspresi yang wajar. ranah afektif terdiri dari penerimaan, partisipasi, penilaian, dan penentuan sikap, organisasi, dan pembentukan pola hidup.

Ranah psikomotor berorientasi kepada ketrampilan fisik, ketrampilan motorik, atau ketrampilan tangan yang berhubungan dengan anggota tubuh atau tindakan yang memerlukan koordinasi antara syaraf dan otot. Ranah psikomotor terdiri dari tujuh jenis perilaku yaitu: persepsi, kesiapan, gerakan terbimbing, gerakan yang terbiasa, gerakan kompleks, penyesuaian pola gerakan, dan kreativitas.

Dari uraian di atas dapat diambil kesimpulan bahwa hasil belajar adalah suatu hasil yang telah diperoleh atau dicapai dari aktivitas yang telah dilakukan atau dikerjakan.

Dari beberapa penjelasan yang dikemukakan di atas maka peneliti menyimpulkan bahwa Hasil Belajar adalah hasil yang dicapai setelah siswa melakukan kegiatan belajar sehingga ada perubahan-perubahan dalam pengetahuan, pemahaman, keterampilan dan sikap siswa atau Hasil Belajar adalah Hasil Belajar yang diperoleh siswa di akhir pembelajaran yang disebabkan oleh suatu proses belajar. Dengan mengetahui Hasil Belajar siswa dapat diketahui kedudukan siswa dalam kelas, apakah siswa itu termasuk kelompok siswa yang pandai, sedang atau kurang. Hasil Belajar seseorang sesuai dengan tingkat keberhasilan sesuatu dalam mempelajari materi pelajaran yang dinyatakan dalam bentuk nilai atau raport setiap bidang studi setelah mengalami proses belajar mengajar.

\section{Metodelogi}

Penelitian ini dilaksanakan di MTsN 1 Aceh Utara. Peneliti memilih tempat ini karena tempat ini merupakan unit kerja atau tempat dinas peneliti sehingga mempermudah kerjasama antar peneliti, pihak madrasah, objek yang diteliti serta untuk menghemat waktu dan biaya. Subjek penelitian ditetapkan pada siswa-siswi Kelas IX/2 MTsN 1 Aceh Utara tahun pelajaran 2017/2018, dengan jumlah dengan jumlah 38 siswa yang terdiri dari 11 siswa laki-laki dan 17 siswa perempuan.

Berdasarkan permasalahan yang diajukan dalam penelitian yang lebih mengutamakan pada peningkatan hasil belajar siswa, aktifitas guru dalam pembelajaran, dan respon siswa terhadap penerapan model pembelajaran kooperatif tipe Jigsaw, maka jenis penelitian ini termasuk Penelitian Tindakan Kelas (PTK) Karena peneliti terlibat langsung dari awal pembelajaran hingga akhir pembelajaran pada materi gerak benda

$\overline{\text { Al-Madaris, Volume 1 (1), } 2020}$ 
Jadi menurut peneliti, penelitian tidakan kelas adalah salah satu upaya guru dalam bentuk berbagai kegiatan yang dilakukan untuk memperbaiki dan meningkatkan mutu pembelajaran dikelas.

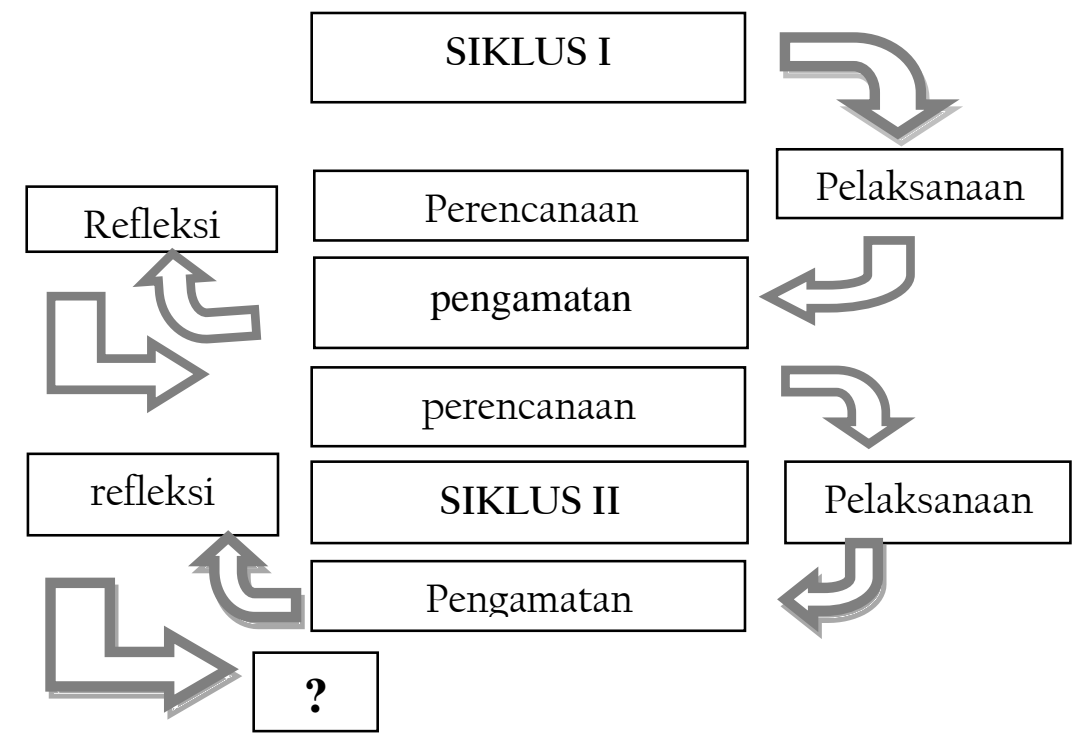

Secara umum penelitian ini dilakukan dalam dua siklus, dimana setiap siklus terdapat 4 tahapan. Menurut Arikunto (2013:137) “Tahap-tahapnya adalah:

1. Perencanaan

2. Pelaksanaan Tindakan

3. Pengamatan atau Observasi

4. Refleksi

\section{Hasil Penelitian}

\section{Siklus I}

Pertemuan 1 dan 2

Hal-hal yang dibahas atau dianalisis diunsur ini berkenaan dengan hasil observasi terhadap siswa dan terhadap guru.

1) Analisis hasil observasi terhadap siswa Sebagaimana telah disebukan di atas bahwa hal yang dilakukan terhadap siswa ada 2 hal, yakni observasi aktivitas Hasil Belajar siswa dan tes/ujian materi.

a) Observasi aktivitas siswa

Observasi aktivitas siswa terdiri dari 3 unsur, yakni aktivitas positif, aktivitas negatif, dan aktivitas biasa-biasa saja. Dari masing-masing aktifitas ini diukur dengan skor persen berdasarkan jumlah siswa. Ketiga aktivitas ini dituangkan dalam bentuk tabel sebagai berikut:

Tabel 4.1

Aktivitas Positif (Siklus I)

\begin{tabular}{ccccc}
\hline \multirow{2}{*}{ NO } & \multicolumn{2}{c}{ PERTEMUAN I } & \multicolumn{2}{c}{ PERTEMUAN 2 } \\
\cline { 2 - 5 } & JLH & PERSEN- & JLH & PERSEN- \\
& SISWA & TASI & SISWA & TASI \\
\hline
\end{tabular}

$\overline{\text { Al-Madaris, Volume l (1), } 2020}$ 


\begin{tabular}{clrrrr}
\hline 1. & Siswa bertanya & $4 / 38$ & $10,53 \%$ & $6 / 38$ & $15,79 \%$ \\
\hline 2. & Siswa menanggapi & $4 / 38$ & $10,53 \%$ & $5 / 38$ & $13,16 \%$ \\
\hline 3. & Siswa membantu temannya & $3 / 38$ & $7,89 \%$ & $4 / 38$ & $10,53 \%$ \\
\hline 4. & Siswa menjawab pertanyaan & $3 / 38$ & $7,89 \%$ & $3 / 38$ & $7,89 \%$ \\
\hline 5. & $\begin{array}{l}\text { Siswa yang membaca sumber } \\
\text { belajar }\end{array}$ & $4 / 38$ & $10,53 \%$ & $3 / 38$ & $7,89 \%$ \\
\hline 6. & Aktif dalam kelompok & $3 / 38$ & $7,89 \%$ & $3 / 38$ & $7,89 \%$ \\
\hline 7. & Siswa bertanya hal integratif & $3 / 38$ & $7,89 \%$ & $3 / 38$ & $7,89 \%$ \\
\hline \multicolumn{2}{c}{ Jumlah } & $24 / 38$ & $63,16 \%$ & $27 / 38$ & $71,05 \%$ \\
\hline RATA-RATA & $9,02 \%$ & $10,15 \%$ \\
\hline
\end{tabular}

Tabel 4.2

Aktivitas Negatif (Siklus I)

\begin{tabular}{cccccc}
\hline \multirow{2}{*}{ NO } & \multirow{2}{*}{ AKTIVITAS } & \multicolumn{2}{c}{ PERTEMUAN 1 } & \multicolumn{2}{c}{ PERTEMUAN 2 } \\
\cline { 3 - 6 } & & JLH & PERSEN- & JLH & PERSEN- \\
& & SISWA & TASI & SISWA & TASI \\
\hline l. & Siswa ngantuk & $3 / 38$ & $7,89 \%$ & $2 / 38$ & $5,26 \%$ \\
\hline 2. & Siswa mengganggu temannya & $3 / 38$ & $7,89 \%$ & $3 / 38$ & $7,89 \%$ \\
\hline 3. & Siswa yang ribut & $4 / 38$ & $10,53 \%$ & $3 / 38$ & $7,89 \%$ \\
\hline \multicolumn{2}{c}{ Jumlah } & $10 / 38$ & $26,32 \%$ & $8 / 38$ & $21,05 \%$ \\
\hline RATA-RATA & \multicolumn{4}{c}{$\mathbf{3} \%$} \\
\hline
\end{tabular}

Tabel 4.3

Aktivitas Biasa-Biasa (Siklus I)

\begin{tabular}{|c|c|c|c|c|c|}
\hline \multirow[b]{2}{*}{ NO } & \multirow[b]{2}{*}{ AKTIVITAS } & \multicolumn{2}{|c|}{ PERTEMUAN I } & \multicolumn{2}{|c|}{ PERTEMUAN 2} \\
\hline & & $\begin{array}{l}\text { JLH } \\
\text { SISWA }\end{array}$ & $\begin{array}{l}\text { PERSEN- } \\
\text { TASI }\end{array}$ & $\begin{array}{l}\text { JLH } \\
\text { SISWA }\end{array}$ & $\begin{array}{l}\text { PERSEN- } \\
\text { TASI }\end{array}$ \\
\hline 1. & Diam-diam saja/malas & $4 / 38$ & $10,53 \%$ & $3 / 38$ & $7,89 \%$ \\
\hline 2. & & & & & \\
\hline & Jumlah & $4 / 38$ & $10,53 \%$ & $3 / 38$ & $7,89 \%$ \\
\hline & RATA-RATA & & $10,53 \%$ & & $7,89 \%$ \\
\hline
\end{tabular}

Tabel 4.4

Rekapitulasi Aktivitas Siswa (Siklus I)

\begin{tabular}{clcc}
\hline \multirow{2}{*}{ NO } & \multirow{2}{*}{ AKTIVITAS } & PERTEMUAN 1 & PERTEMUAN 2 \\
\cline { 2 - 4 } & & PERSENTASI & PERSENTASI \\
\hline 1. & Aktivitas positif & $9,02 \%$ & $10,15 \%$ \\
\hline 2. & Aktivitas negatif & $8,77 \%$ & $7,02 \%$ \\
\hline 3. & Biasa-biasa saja/malas & $10,53 \%$ & $7,89 \%$ \\
\hline
\end{tabular}

1) Hasil tes/ujian

Hasil tes disini adalah hasil ulangan harian siswa, hasilnya dituangkan dalam tabel berikut ini.

Tabel 4.5

Hasil Ulangan Harian Siswa (Siklus I)

\section{Pertemuan 1}

No.
Pertemuan 2

$\% \quad \begin{aligned} & \text { Jumlah } \\ & \text { Siswa yang Jumlah }\end{aligned}$




\begin{tabular}{cccccccc}
\hline & \multicolumn{7}{c}{ benar } \\
\hline 1. & Soal 1 & 18 & $18 / 38$ & $47,4 \%$ & 25 & $25 / 38$ & $65,8 \%$ \\
\hline 2 & Soal 2 & 15 & $15 / 38$ & $39,5 \%$ & 21 & $21 / 38$ & $55,3 \%$ \\
\hline 3. & Soal 3 & 18 & $18 / 38$ & $47,4 \%$ & 21 & $21 / 38$ & $55,3 \%$ \\
\hline 4 & Soal 4 & 15 & $15 / 38$ & $39,5 \%$ & 18 & $18 / 38$ & $47,4 \%$ \\
\hline 5. & Soal 5 & 17 & $17 / 38$ & $44,7 \%$ & 22 & $22 / 38$ & $57,9 \%$ \\
\hline & Jumlah & & $218,4 \%$ & & $281,6 \%$ \\
\hline & Persentasi & $43,7 \%$ & & $56,3 \%$ \\
\hline
\end{tabular}

Grafik hasil tes siswa dapat dilihat berikut ini:

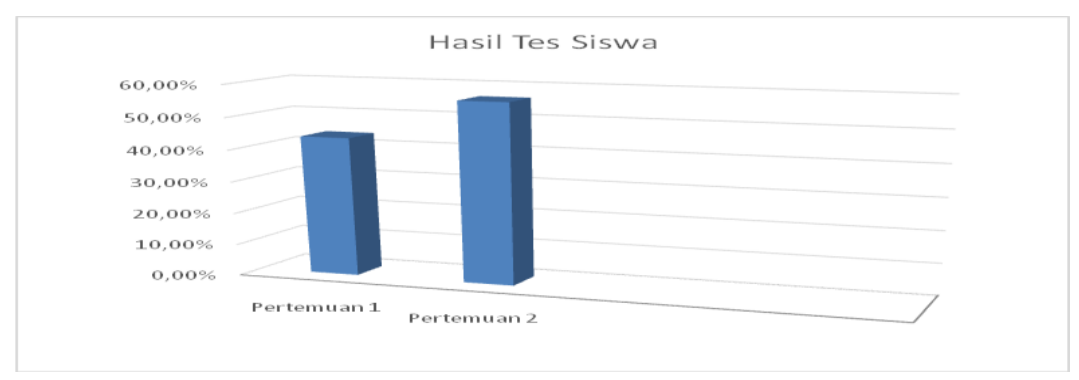

\section{Gambar. 5. Grafik Hasil Tes Siswa Siklus I}

2) Analisis hasil observasi terhadap guru

Sasaran observasi yang dilakukan oleh observer terhadap guru dibagi kepada 4 unsur, yakni: terhadap persiapan pembelajaran, terhadap presentasi, terhadap Model Pembelajaran, dan karakteristik guru. Observasi terhadap persiapan pembelajaran, memiliki 6 unsur. Untuk presentasi memiliki 5 unsur, metode pemelajaran 5 unsur, dan karakteristik guru memiliki 6 unsur. Unsur-unsur itu dituangkan dalam bentuk tabel berikut ini.

Tabel 4.6

Observasi Persiapan (Siklus I)

\begin{tabular}{|c|c|c|c|c|c|c|c|}
\hline \multirow[t]{2}{*}{ No } & \multirow[t]{2}{*}{ Aspek Penilaian } & \multicolumn{3}{|c|}{ Pertemuan 1} & \multicolumn{3}{|c|}{ Pertemuan 2} \\
\hline & & $\begin{array}{l}\text { Kate } \\
\text { gori }\end{array}$ & Skor & $\%$ & $\begin{array}{l}\text { Kate } \\
\text { gori }\end{array}$ & Skor & $\%$ \\
\hline 1. & $\begin{array}{l}\text { Guru mempersiapkan rencana } \\
\text { pelaksanaan pembelajaran } \\
\text { (RPP) dengan seksama }\end{array}$ & SL & 4 & $100 \%$ & SL & 4 & $100 \%$ \\
\hline 2. & $\begin{array}{l}\text { Tujuan pembelajarannya } \\
\text { dinyatakan dalam kalimat yang } \\
\text { jelas dalam RPP }\end{array}$ & SR & 3 & $75 \%$ & SL & 4 & $100 \%$ \\
\hline 3. & $\begin{array}{l}\text { Materi pembelajaran yang akan } \\
\text { diberikan memiliki kaitan atau } \\
\text { dapat dikaitkan dengan materi } \\
\text { pembelajaran sebelumnya }\end{array}$ & SR & 3 & $75 \%$ & SR & 3 & $75 \%$ \\
\hline 4. & Guru mempersiapkan media & SR & 3 & $75 \%$ & SR & 3 & $75 \%$ \\
\hline
\end{tabular}




\begin{tabular}{|c|c|c|c|c|c|c|c|}
\hline & pembelajaran & & & & & & \\
\hline 5. & $\begin{array}{l}\text { Guru mempersiapkan seting } \\
\text { kelas untuk pembelajaran }\end{array}$ & SR & 3 & $75 \%$ & SL & 4 & $100 \%$ \\
\hline 6. & $\begin{array}{l}\text { Guru mempersiapkan siswa } \\
\text { secara fisik dan mental }\end{array}$ & SR & 3 & $75 \%$ & SR & 3 & $75 \%$ \\
\hline & Jumlah & & & $475 / 6$ & & & $525 / 6$ \\
\hline & Rata-Rata & & & $79 \%$ & & & $88 \%$ \\
\hline
\end{tabular}

Tabel 4.7

Observasi Presentasi (Siklus I)

\begin{tabular}{|c|c|c|c|c|c|c|c|}
\hline \multirow[t]{2}{*}{ No } & \multirow[t]{2}{*}{ Aspek Penilaian } & \multicolumn{3}{|c|}{ Pertemuan 1} & \multicolumn{3}{|c|}{ Pertemuan 2} \\
\hline & & $\begin{array}{l}\text { Kate } \\
\text { gori }\end{array}$ & Skor & $\%$ & $\begin{array}{l}\text { Kate } \\
\text { gori }\end{array}$ & Skor & $\%$ \\
\hline 1. & $\begin{array}{l}\text { Guru menyampaikan tujuan } \\
\text { pembelajaran yang hendak } \\
\text { dicapai }\end{array}$ & SL & 4 & $100 \%$ & SL & 4 & $100 \%$ \\
\hline 2. & $\begin{array}{l}\text { Guru memotivasi siswa, } \\
\text { menarik perhatian agar } \\
\text { mengikuti proses pembelajaran } \\
\text { dengan baik }\end{array}$ & SR & 3 & $75 \%$ & SR & 3 & $75 \%$ \\
\hline 3 & $\begin{array}{l}\text { Guru menjelaskan materi } \\
\text { pembelajaran dengan teknik- } \\
\text { teknik tertentu sehingga jelas } \\
\text { dan mudah dipahami siswa }\end{array}$ & SR & 3 & $75 \%$ & SR & 3 & $75 \%$ \\
\hline 4. & $\begin{array}{l}\text { Pembelajaran dilaksanakan } \\
\text { dalam langkah-langkah dan } \\
\text { urutan yang logis }\end{array}$ & SR & 3 & $75 \%$ & SL & 4 & $100 \%$ \\
\hline 5. & $\begin{array}{l}\text { Petunjuk-petunjuk } \\
\text { pembelajaran singkat dan jelas } \\
\text { sehingga mudah dipahami }\end{array}$ & SR & 3 & $75 \%$ & SR & 3 & $75 \%$ \\
\hline & Jumlah & & & $400 / 5$ & & & $425 / 5$ \\
\hline & Rata-Rata & & & $80 \%$ & & & $85 \%$ \\
\hline
\end{tabular}

Tabel 4.8

Observasi Model Pembelajaran (Siklus I)

\begin{tabular}{|c|c|c|c|c|c|c|c|}
\hline \multirow[t]{2}{*}{ No } & \multirow[t]{2}{*}{ Aspek Penilaian } & \multicolumn{3}{|c|}{ Pertemuan 1} & \multicolumn{3}{|c|}{ Pertemuan 2} \\
\hline & & $\begin{array}{l}\text { Kate } \\
\text { gori }\end{array}$ & Skor & $\%$ & $\begin{array}{l}\text { Kate } \\
\text { gori }\end{array}$ & Skor & $\%$ \\
\hline 1. & $\begin{array}{l}\text { Pembelajaran dilakukan secara } \\
\text { bervariasi selama alokasi waktu } \\
\text { yang tersedia, tidak monoton } \\
\text { dan membosankan }\end{array}$ & SR & 3 & $75 \%$ & SL & 4 & $100 \%$ \\
\hline 2. & $\begin{array}{l}\text { Apabila terjadi suatu } \\
\text { permasalahan maka guru dapat } \\
\text { bertindak dengan mengambil } \\
\text { keputusan terbaik agar } \\
\text { pembelajaran tetap berlangsung } \\
\text { secara efektif dan efisien }\end{array}$ & SR & 3 & $75 \%$ & SR & 3 & $75 \%$ \\
\hline 3 & $\begin{array}{l}\text { materi pembelajaran sesuai } \\
\text { dengan tujuan pembelajaran } \\
\text { yang telah ditetapkan }\end{array}$ & SL & 4 & $100 \%$ & SL & 4 & $100 \%$ \\
\hline 4. & $\begin{array}{l}\text { selama pembelajaran } \\
\text { berlangsung guru tidak hanya }\end{array}$ & SR & 3 & $75 \%$ & SR & 3 & $75 \%$ \\
\hline
\end{tabular}




\begin{tabular}{|c|c|c|c|c|c|c|c|}
\hline & $\begin{array}{l}\text { berada pada posisi tertentu } \\
\text { tetapi bergerak secara dinamis } \\
\text { di dalam kelasnya }\end{array}$ & & & & & & \\
\hline \multirow[t]{3}{*}{5.} & $\begin{array}{l}\text { Apabila tampak ada siswa yang } \\
\text { membutuhkan bantuannya di } \\
\text { bagian-bagian tertentu kelas, } \\
\text { maka guru harus bergerak dan } \\
\text { menghampiri secara berimbang } \\
\text { dan tidak terfokus hanya pada } \\
\text { beberapa gelintir siswa saja }\end{array}$ & SR & 3 & $75 \%$ & SR & 3 & $75 \%$ \\
\hline & Jumlah & & & $400 / 5$ & & & $425 / 5$ \\
\hline & Rata-Rata & & & $80 \%$ & & & $85 \%$ \\
\hline
\end{tabular}

Tabel 4.9

Observasi Karakteristik Guru (Siklus I)

\begin{tabular}{|c|c|c|c|c|c|c|c|}
\hline \multirow[t]{2}{*}{ No } & \multirow[t]{2}{*}{ Aspek Penilaian } & \multicolumn{3}{|c|}{ Pertemuan 1} & \multicolumn{3}{|c|}{ Pertemuan 2} \\
\hline & & $\begin{array}{l}\text { Kate } \\
\text { gori }\end{array}$ & Skor & $\%$ & $\begin{array}{l}\text { Kate } \\
\text { gori }\end{array}$ & Skor & $\%$ \\
\hline 1. & $\begin{array}{l}\text { Guru sabar terutama untuk } \\
\text { memancing respon siswa }\end{array}$ & SR & 3 & $75 \%$ & SL & 4 & $100 \%$ \\
\hline 2. & $\begin{array}{l}\text { Guru berupaya memancing } \\
\text { siswa agar terlibat aktif dalam } \\
\text { pembelajaran }\end{array}$ & SR & 3 & $75 \%$ & SR & 3 & $75 \%$ \\
\hline 3 & Guru bersikap tegas dan jelas & SR & 3 & $75 \%$ & SR & 3 & $75 \%$ \\
\hline 4. & $\begin{array}{l}\text { Penampilan guru menarik dan } \\
\text { tidak membosankan }\end{array}$ & SR & 3 & $75 \%$ & SR & 3 & $75 \%$ \\
\hline 5. & $\begin{array}{l}\text { Guru menggunakan bahasa } \\
\text { yang baik dan berterima }\end{array}$ & SR & 3 & $75 \%$ & SR & 3 & $75 \%$ \\
\hline 6. & $\begin{array}{l}\text { Guru selalu menunjukkan } \\
\text { bahwa ia adalah seorang yang } \\
\text { selalu punya inisiatif, kreatif, } \\
\text { dan berprakarsa }\end{array}$ & SR & 3 & $75 \%$ & SR & 3 & $75 \%$ \\
\hline & Jumlah & & & $450 / 6$ & & & $475 / 6$ \\
\hline & Rata-Rata & & & $75 \%$ & & & $79 \%$ \\
\hline
\end{tabular}

\section{Rekapitulasi Aktivitas Guru (Siklus I)}

1. Observasi Persiapan Pembelajaran

2. Observasi Presentasi Pembelajaran

3. Observasi Model Pembelajaran

Pertemuan 1

$79 \%$

$80 \%$

$80 \%$

$75 \%$

Rekapitulasi Aktivitas Guru
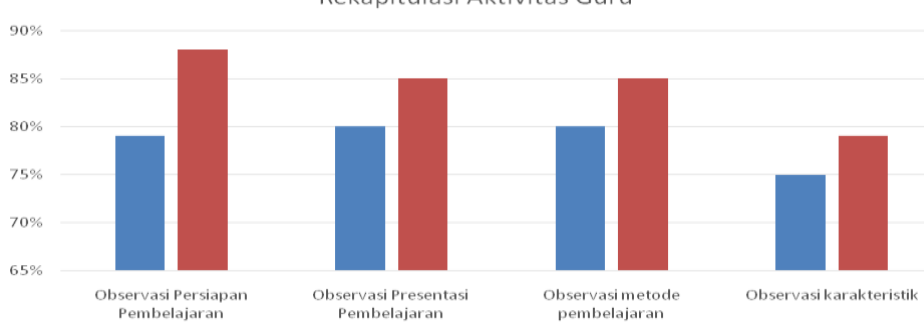

- Pertemuan 1 = Pertemuan 2
Pertemuan 2

$88 \%$

$85 \%$

$85 \%$

$79 \%$

Gambar. 6. Grafik Rekapitulasi Aktivitas Guru Siklus I Tabel 4.10

$\overline{\text { Al-Madaris, Volume 1 (1), } 2020}$ 
Hasil Pembahasan Pertemuan 1 dan 2 (Siklus I)

\begin{tabular}{|c|c|c|c|c|c|}
\hline $\mathrm{NO}$ & KELOMPOK & $\begin{array}{c}\text { JENIS } \\
\text { KEGIATAN }\end{array}$ & $\begin{array}{c}\text { HASIL } \\
\text { KEGIATAN } \\
\text { (1) }\end{array}$ & $\begin{array}{c}\text { HASIL } \\
\text { KEGIATAN } \\
(2)\end{array}$ & KET \\
\hline \multirow[t]{3}{*}{1.} & \multirow[t]{3}{*}{ Aktivitas Siswa } & $\begin{array}{l}\text { Aktivitas } \\
\text { positif }\end{array}$ & $9,02 \%$ & $10,15 \%$ & $\begin{array}{l}\text { Perlu } \\
\text { peningkatan }\end{array}$ \\
\hline & & $\begin{array}{l}\text { Aktifitas } \\
\text { negatif }\end{array}$ & $8,77 \%$ & $7,02 \%$ & $\begin{array}{l}\text { Perlu } \\
\text { penurunan }\end{array}$ \\
\hline & & $\begin{array}{l}\text { Biasa-biasa } \\
\text { saja/malas }\end{array}$ & $10,53 \%$ & $7,89 \%$ & $\begin{array}{l}\text { Perlu } \\
\text { perubahan } \\
\text { positif }\end{array}$ \\
\hline 2. & Hasil Ujian Siswa & & $43,7 \%$ & $56,3 \%$ & $\begin{array}{l}\text { Perlu } \\
\text { peningkatan } \\
\text { prestasi }\end{array}$ \\
\hline \multirow[t]{4}{*}{3.} & \multirow[t]{4}{*}{$\begin{array}{l}\text { Observasi } \\
\text { aktivitas guru }\end{array}$} & $\begin{array}{l}\text { Persiapan } \\
\text { pembelajaran }\end{array}$ & $79 \%$ & $88 \%$ & $\begin{array}{l}\text { Perlu } \\
\text { peningkatan }\end{array}$ \\
\hline & & $\begin{array}{l}\text { Presentasi } \\
\text { pembelajaran }\end{array}$ & $80 \%$ & $85 \%$ & $\begin{array}{l}\text { Perlu } \\
\text { peningkatan }\end{array}$ \\
\hline & & $\begin{array}{l}\text { Metode } \\
\text { pembelajaran }\end{array}$ & $80 \%$ & $85 \%$ & $\begin{array}{l}\text { Perlu } \\
\text { peningkatan }\end{array}$ \\
\hline & & $\begin{array}{l}\text { Karakteristik } \\
\text { guru }\end{array}$ & $75 \%$ & $79 \%$ & $\begin{array}{l}\text { Perlu } \\
\text { peningkatan }\end{array}$ \\
\hline
\end{tabular}

\section{Siklus II}

Pertemuan 1 dan 2

Hal-hal yang dibahas atau dianalisis diunsur ini berkenaan dengan hasil observasi terhadap siswa dan terhadap guru.

1) Analisis hasil observasi terhadap siswa

Sebagaimana telah disebukan di atas bahwa hal yang dilakukan terhadap siswa ada 2 hal, yakni observasi aktivitas Hasil Belajar siswa dan tes/ujian materi.

a) Observasi aktivitas siswa

Observasi aktivitas siswa terdiri dari 3 unsur, yakni aktivitas positif, aktivitas negatif, dan aktivitas Biasa-biasa saja/malas. Dari masing-masing aktifitas ini diukur dengan skor persen berdasarkan jumlah siswa. Ketiga aktivitas ini dituangkan dalam bentuk tabel sebagai berikut:

Tabel 4.11

Aktivitas Positif (Siklus II)

\begin{tabular}{|c|c|c|c|c|c|}
\hline \multirow[b]{2}{*}{ NO } & \multirow[b]{2}{*}{ AKTIVITAS } & \multicolumn{2}{|c|}{ PERTEMUAN 1} & \multicolumn{2}{|c|}{ PERTEMUAN 2} \\
\hline & & $\begin{array}{c}\text { JLH } \\
\text { SISWA }\end{array}$ & $\begin{array}{l}\text { PERSEN- } \\
\text { TASI }\end{array}$ & $\begin{array}{l}\text { JLH } \\
\text { SISWA }\end{array}$ & $\begin{array}{l}\text { PERSEN- } \\
\text { TASI }\end{array}$ \\
\hline 1. & Siswa bertanya & $7 / 38$ & $18,42 \%$ & $8 / 38$ & $21,05 \%$ \\
\hline 2. & Siswa menanggapi & $6 / 38$ & $15,79 \%$ & $6 / 38$ & $15,79 \%$ \\
\hline 3. & Siswa membantu temannya & $5 / 38$ & $13,16 \%$ & $6 / 38$ & $15,79 \%$ \\
\hline 4. & Siswa menjawab pertanyaan & $4 / 38$ & $10,53 \%$ & $5 / 38$ & $13,16 \%$ \\
\hline 5. & $\begin{array}{l}\text { Siswa yang membaca sumber } \\
\text { belajar }\end{array}$ & $5 / 38$ & $13,16 \%$ & $4 / 38$ & $10,53 \%$ \\
\hline 6. & Aktif dalam kelompok & $4 / 38$ & $10,53 \%$ & $4 / 38$ & $10,53 \%$ \\
\hline 7. & Siswa bertanya hal integratif & $3 / 38$ & $7,89 \%$ & $5 / 38$ & $13,16 \%$ \\
\hline
\end{tabular}

Al-Madãris, Volume 1 (1), 2020 


\begin{tabular}{|c|c|c|c|c|}
\hline Jumlah & $34 / 38$ & $89,29 \%$ & $38 / 38$ & $100,00 \%$ \\
\hline RATA-RATA & & $12,76 \%$ & & $14,29 \%$ \\
\hline
\end{tabular}

2) Hasil tes/ujian

Hasil tes disini adalah hasil ulangan harian siswa, hasilnya dituangkan dalam tabel berikut ini.

Tabel 4.15

Hasil Ulangan Harian Siswa (Siklus II)

\begin{tabular}{|c|c|c|c|c|c|c|c|}
\hline \multirow[b]{2}{*}{ No. } & \multirow[b]{2}{*}{ SOAL } & \multicolumn{3}{|c|}{ Pertemuan 1} & \multicolumn{3}{|c|}{ Pertemuan 2} \\
\hline & & $\begin{array}{c}\text { Jumlah } \\
\text { Siswa yang } \\
\text { benar }\end{array}$ & Jumlah & $\%$ & $\begin{array}{c}\text { Jumlah } \\
\text { Siswa yang } \\
\text { benar }\end{array}$ & Jumlah & $\%$ \\
\hline 1. & Soal 1 & 33 & $33 / 38$ & $86,8 \%$ & 36 & $36 / 38$ & $94,7 \%$ \\
\hline 2 & Soal 2 & 32 & $32 / 38$ & $84,2 \%$ & 36 & $36 / 38$ & $94,7 \%$ \\
\hline 3. & Soal 3 & 28 & $28 / 38$ & $73,7 \%$ & 33 & $33 / 38$ & $86,8 \%$ \\
\hline 4 & Soal 4 & 26 & $26 / 38$ & $68,4 \%$ & 34 & $34 / 38$ & $89,5 \%$ \\
\hline 5. & Soal 5 & 26 & $26 / 38$ & $68,4 \%$ & 33 & $33 / 38$ & $86,8 \%$ \\
\hline \multirow{2}{*}{\multicolumn{2}{|c|}{ Jumlah }} & & & $381,6 \%$ & & & $452,6 \%$ \\
\hline & & Persentasi & & $76,3 \%$ & & & $90,5 \%$ \\
\hline
\end{tabular}

3) Analisis hasil observasi terhadap guru

Sasaran observasi yang dilakukan oleh observer terhadap guru dibagi kepada 4 unsur, yakni: terhadap persiapan pembelajaran, terhadap presentasi, terhadap Model Pembelajaran, dan karakteristik guru. Observasi terhadap persiapan pembelajaran, memiliki 6 unsur. Untuk presentasi memiliki 5 unsur, metode pemelajaran 5 unsur, dan karakteristik guru memiliki 6 unsur. Unsur-unsur itu dituangkan dalam bentuk tabel berikut ini.

\section{Program Perubahan}

Tabel 4.21

Program Perubahan

\begin{tabular}{ccll}
\hline No & Fokus perubahan & \multicolumn{1}{c}{ Unsur kelemahan } & \multicolumn{1}{c}{ Program perubahan } \\
\hline 1. & Sikap & $\begin{array}{l}\text { Siswa tidak semua aktif } \\
\text { dan memahami materi } \\
\text { dalam pembelajaran }\end{array}$ & Dapat lebih memotivasi siswa \\
\hline 2. & Model Pembelajaran & $\begin{array}{l}\text { Menggunakan metode } \\
\text { konvensional }\end{array}$ & $\begin{array}{l}\text { Menggunakan model } \\
\text { pembelajaran Jigsaw }\end{array}$ \\
\hline 3. & Media pembelajaran & $\begin{array}{l}\text { Guru sebagai } \\
\text { penceramah }\end{array}$ & $\begin{array}{l}\text { Peserta didik secara } \\
\text { berkelompok berperan dalam } \\
\text { pembelajaran sedangkan guru } \\
\text { berperan sebagai pemonitor dan } \\
\text { fasilitator }\end{array}$ \\
\hline 4. & Alat peraga & Guru dan buku pegangan & $\begin{array}{l}\text { Lembar permasalahan, buku } \\
\text { pegangan, guru }\end{array}$ \\
\hline
\end{tabular}

$\overline{\text { Al-Madãris, Volume l (1), } 2020}$ 
Setiap peserta didik

menggunakan panduan

permasalahan materi yang

Pemberian tugas, guru

$5 \quad$ Istrumen

menyimpulkan inti

dibahas, menjawab soal, peserta

didik bersama guru membuat

kesimpulan terhadap materi

pelajaran.

Lembar observasi siswa dan guru

\section{E. Pembahasan}

Berdasarkan hasil analisis di atas menunjukkan bahwa pada pertemuan pertama siklus I dari semua unsur belum mencapai nilai standar minimal $=76 \%$, yaitu hasil ulangan siswa masih memperoleh nilai rata-rata 43,7 \%. Oleh karenanya menjadi perhatian untuk meningkatkan dan mengembangkan semua unsur pada pertemuan berikutnya, yakni pertemuan kedua. Pada pertemuan kedua adanya perkembangan bila dibandingkan dengan hasil pertemuan pertama perkembangannya yaitu berdasarkan hasil ulangan harian siswa memperoleh nilai rata-rata 56,3\%.

Data di atas menunjukkan adanya peningkatan namun belum mencapai standar minimal (76 \%). Untuk meningkatkan perolehan hasil penelitian maka dilanjutkan dengan siklus kedua. Pada pertemuan pertama adanya peningkatan dari pertemuan kedua siklus I. Peningkatan itu yaitu berasarkan hasil ulangan siswa pertemuan kedua siklus I nilai rata-rata meningkat menjadi 76,3\%.

Pertemuan kesatu dari siklus II sudah menghasilkan sesuatu yang menggembirakan. Untuk mendapatkan kemahiran puncak maka dilakukan pertemuan kedua dari siklus II. Hasilnya sangat menggembirakan sebagai berikut: berdasarkan hasil ulangan siswa sudah memperoleh nilai rata-rata 90,5 $\%$.

\section{F. Kesimpulan}

Berdasarkan hasil penelitian dan pembahasan dalam penelitian ini, maka dalam penelitian ini peneliti dapat menarik kesimpulan yaitu sebagai berikut:

1. Penerapan Model Pembelajaran Jigsaw terhadap Materi Teks Eksemplum di Kelas IX/2 MTsN 1 Aceh Utara ternyata dapat meningkatkan Hasil Belajar siswa. Adapun perolehan Hasil Belajar siswa dapat dilihat secara rata-rata di kelas yang menunjukkan peningkatan dari siklus I sampai siklus II, hasil akhir di atas standar minimal (76\%) yaitu 90,5\%. Peningkatan Hasil Belajar siswa pada materi Teks Eksemplum juga dapat dilihat dari hasil pengamatan guru yang menunjukkan bahwa dengan adanya pelaksanaan tindakan dalam penelitian ini hampir seluruh siswa dapat meguasai materi Teks Eksemplum dengan baik dan benar.

2. Sebelum penerapan model pembelajaran Jigsaw sebagai upaya peningkatan Hasil Belajar siswa, awalnya masih terdapat kendala yaitu masih rendahnya minat dan motivasi siswa dalam belajar Materi Teks Eksemplum. Sehingga dalam pelaksanaan tindakan dilakukan upaya perbaikan untuk 
dapat mengatasi permasalahan tersebut yaitu dengan menggunakan model pembelajaran Jigsaw berupa pembahasan materi dengan membentuk kelompok asal dan kelompok ahli untuk mendiskusikan materi yang akan dipelajari. Di mana pada akhir siklus diperoleh hasil selain tindakan ini dapat meningkatkan Hasil Belajar siswa terhadap Materi Teks Eksemplum seluruh siswa juga dapat meningkatkan minat dan motivasi dalam belajar Materi Teks Eksemplum.

3. Dalam penerapan model pembelajaran Jigsaw dibutuhkan kemampuan guru dalam melakukan variasi untuk dapat menarik minat dan motivasi siswa dalam pembelajaran Materi Teks Eksemplum, sehingga selain metode ini sangat efektif digunakan dalam upaya peningkatan Hasil Belajar pada materi Teks Eksemplum juga diharapkan dapat meningkatkan minat dan motivasi siswa dalam belajar Materi Teks Eksemplum.

\section{BIBLIOGRAFI}

Agus suprijono. 2010. Cooperative Learning. Yogyakarta. Pustaka Media.

Anis, S.Pd.M.M.Pd. 2016. Meningkatkan Hasil Belajar Siswa Pada Menulis Teks Eksemplum

Dengan Model Pembelajaran Jigsaw di Kelas IX-B SMPN 1 Tanjung Siang. Tanjung

Siang: Jurnal MPD, Volume 8, Nomor l, Februari 2017

Arikunto, Suharsimi, 2009. Penelitian Tindakan Kelas. Jakarta: Rineka Cipta.

Aqib, Zainal. 2011. Penelitian Tindakan Kelas. Bandung: Yrama Media.

Darsono M. 2000.Belajar dan Pembelajaran. Semarang: IKIP semarang Press.

Depdiknas. 2004. Pendekatan Konstekstual. Jakarta: Direktorat Pendidikan Lanjutan Pertama. Direktorat Jenderal Pendidikan Dasar dan Menengah.

Departemen Pendidikan Nasional. 2006. Peraturan Menteri Pendidikan Nasional Republik Indonesia No.22 tahun 2006 tentang Standar Isi. Jakarta : Depdiknas.

Ummah, Dian Hidayatul. t.t. Penerapan Model Pembelajaran Kooperatif Tipe Jigsaw Untuk Meningkatkan Hasil Belajar IPA Siswa Kelas VII di MTsN Podorejo Sumbergempol Tulungagun. Tulungagung : Skripsi Tidak Diterbitkan.

Djamarah, 2006, Strategi Belajar Mengajar, Jakarta: Rineka Cipta.

Dimyati dan Mudjiono. 2002. Belajar dan Pembelajaran. Jakarta: Rineka Cipta dan Depdikbud.

Freddy Rangkuti, 2009, Strategi Promosi Yang Kreatif, Jakarta: Gramedia Pustaka Utama.

H.B. Sutopo, 2006, Metodologi Penelitian Kualitatif: Dasar teori dan Terapannya dalam Penelitian, Surakarta: Universitas. Sebelas Maret.

$\overline{\text { Al-Madãris, Volume 1 (1), } 2020}$ 